\title{
On the Transverse Strength of Ore Carriers
}

\author{
by Masahiro Mori, Member* \\ Takehiko Ohyama** \\ Summary
}

Ryosuke Kanai, Member*

Akira Ono**, Member

\begin{abstract}
When a large ore carrier is floating in the full load condition, a large amount of ore load is acting on the double bottom downwards and a large amount of buoyancy is acting on the wing tank upwards. In this case, it is expected that the relative deflection between the side shell and the longitudinal bulkhead increases and induces large stresses in the transvese rings. According to this. way of thinking, the authors try to calculate the transverse strength of ore carriers including the: relative deflection and the stresses induced by it, and then try to make some considerations upon. the effects of shear rigidity of swash bulkheads and of transverse rings.
\end{abstract}

From these calculations following things are found:

(1) Induced stresses due to relative deflection between side shells and longitudinal bulkheads: can not be neglected.

(2) For the purpose of making relative deflection small, it is not effective to set swash. bulkheads of reinforced transverse ring type, but is effective to set swash bulkheads of per-. forated plane type.

\section{Introduction}

When a large ore carrier is floating in the full load condition, a large amount of ore load is actingon the double bottom downwards and a large amount of buoyancy is acting on the wing tank upwards. In this case it is expected that the relative deflection between the side shell and the longitudinal bulkhead increases and induces large stresses in the transverse rings. The longer the length of wing tank becomes, the larger those induced stresses will become. It is, therefore, necessary to take into consideration not only stresses due to external forces such as ore load and buoyancy but also stresses induced by relative deflection at the same time, when the transverse strength of large ore carriers is examined. As to tankers, this problem has been already discussed ${ }^{1), 2)}$.

In this paper, according to this way of thinking, authors try to estimate the followings :

(1) the amount of these induced stresses in transverse rings,

(2) the effects of shear rigidity of swash bulkheads and of transverse rings on relative deflection.

\section{Process of Calculation}

\section{1 General Considerations}

In order to make an exact calculation of three dimensional strength of ore carriers, it is necessary to decide the unknown reaction forces between longitudinal and transverse members on the condition to make the deformation of longitudinal members equal to that of transverse members on the conjunction points. In this paper the authors consider this problem as follows :

(1) Deformation of Longitudinal Members

Share the external forces reasonably among longitudinal members, then calculate the defromation 原稿受付 昭和 41 年 7 月 10 日

* Hiroshima Technical Institute, Mitsubishi Heavy Industry Co., Ltd.

** Nagasaki Technical Institute, Mitsubishi Heavy Industry Co., Ltd 
of those members as composed parallel beams with spring actions of transverse rings, watertight bulkheads, swash bulkheads, deck plates and bottom plates. This calculation is carried out over all the holds.

(2) Deformation of Transverse Members

Consider, at first, the transverse ring supported by longitudinal members, and then calculate the deformation of transverse members subjected to external loads of 1-transverse spacing.

Next give the forced displacement obtained in section (1) to each support point, and then calculate the deformation of those members. The final deformation of the transverse ring is obtained by superposing above two deformations.

(3) External Loads

Take ore load, hull weight and buoyancy as the loads for longitudinal members. Take ore load and

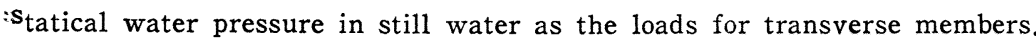

\section{2 Method of Calculation of Transverse Rings}

\section{(1) Deformation of Transverse Rings}

Transverse ring deforms as shown in Fig. 1 (a), when it is in the full load condition in stlll water. "This state is the superposition of two states; one is the state where transverse ring is subjected to
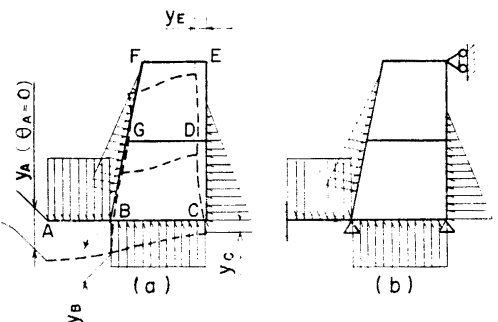

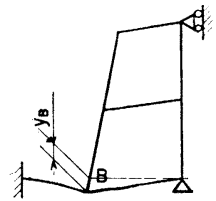

(d)

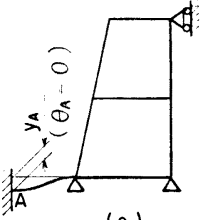

(e)
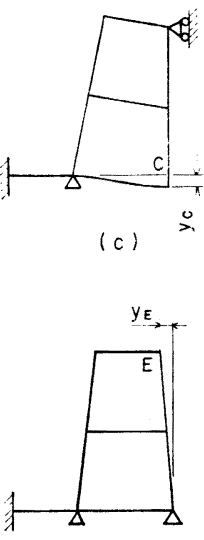

(f)
Fig. 1 Deformation of Transverse Ring external loads with no displacement at all the support points, as shown in Fig. 1 (b), and the other is that where forced displacements equal to those of longitudinal member are given to each support point one by one as shown in Fig. 1(c), (d), (e ), ( f ).

Forced displacements of each support point are influenced by the rigidty and the length of span of the corresponding longitudinal members.

Let us consider next longitudinal member corresponding to the support point $A$, namely, the center girder. It seems to have hardly influence on the transverse members except those near the watertight bulkheads, when the distance of watertight bulkheads is long.

Let us consider next the longitudinal member corresponding to the support point $E$, namely, the deck plate with effective breadth of the side shell and longitudinal bulkhead. Usually there are several hatches between two transverse bulkheads when those distancee is long. This member, therefore, can be considered as a continuous beam with support points at deck struts and transverse bulkheads, so that it has much ability to support transverse members.

The above mentioned things seem to be reasonable from the results of an actual ship test and a model test which have been done by authors before.

Consequently we assume the following iboundary conditions for transverse rings.

(a) The reaction forces from center girder is zero and $\theta_{A}=0$ at the point $A$.

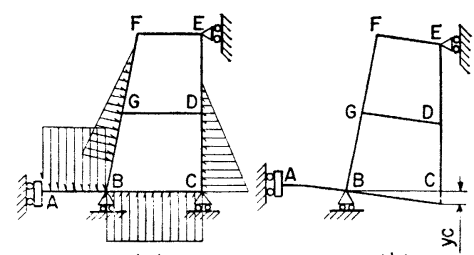

(a)

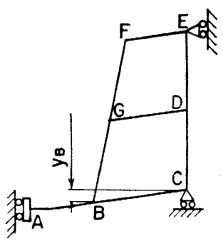

(c)

Fig. 2 Condition of Calculation of Transverse Ring 
(b) The horizontal displacement at the point $E$ is zero.

(c) The displacement at the point $B$ is $y_{B}$.

(d) The displacement at the point $C$ is $y_{c}$.

Thus the condition of calculation of transverse rings becomes as shown in Fig. 2 (a), (b), (c).

(2) Calculation of transverse rings

From preceding considerations, we can say that it is enough for investigating the strength of transverse rings to carry out twc casses of calculation; one is the case shown in Fig. 2 (a), and the other is the case shown in Fig. 2 (b) or (c). Ordinary rigid frame theory ${ }^{3}$ ) is used for this calculation. The assumptions in this calculation are as follows:

(a) Both bending deflection and shear deflection are taken into consideration, but the elongation of structural members is neglected.

(b) The effect of variable cross-sections of structural members are teken into consideration by using the conception of spanpoint.

(c) The neutral axis of structural members lies at the middle of both neutral axes when each neutral axis does not coincide at the joint.

(d) The effective breadth for bottom plates, side shells, longitudinal bulkheads and deck plates is calculated by using H. A. Shades theory.

(e) The cross sectional area of web plate is considered as the effective cross sectional area for shear deflection.

\subsection{Method of Calculation of Relative Deflection}

\section{(1) Division of Structures}

In discussing the relative deflection between longitudinal bulkheads and side shells, we devide the longitudinal members of a ship into two parts; one is the side shell part, and the other is the longitudinal bulkhead part (Fig. 3). The coordinates are taken as shown in Fig. 3. Let the positive direction of $Y$ axis be downward. As to the deflection of structural members, we condsider the elongation of the neutral axes of structural members.

(2) Spring Action of Transverse Rings

When the deflections of the side shell part and the longitudinal bulkhead part are different, transverse rings act as springs, so that reaction forces act between those parts in proportion to their relative deflection.

Denote by $K_{11}$ and $K_{22}$ the forces which are necessary to bring about unit displacement to the point $C$ and the point $B$ respectively, and then denote by $K_{12}$ and $K_{21}$ the reaction forces at the point $B$ and the point $C$ respectively. From the equilibrium of forces we obtain $K_{11}-K_{12}=0, K_{22}-K_{21}=0$. By using reciprocal theorem, we obtain $K_{12}=K_{21}$. Hence the force $P_{12}$ and the force $P_{21}$ which are necessary to bring about the displacement. $y_{1}$ to the point $C$ and the displacement $y_{2}$ to the the point $B$ respectively can be represented in the following forms.

$$
\left.\begin{array}{l}
P_{12}=K_{11} y_{1}-K_{21} y_{2}=K_{12}\left(y_{1}-y_{2}\right) \\
P_{21}=-K_{12} y_{1}+K_{22} y_{2}=-K_{12}\left(y_{1}-y_{2}\right)
\end{array}\right\}
$$

These forces mean the spring action of transverse rings on longitudinal members. For the sake 
of simplicity we assume that these forces act between transverse rings as uniformly distributed forces.

(3) Spring Action of Deck Plates and Botiom Plates

Shearing forces act in deck plates and bottom plates in proportion to the difference of longitudinal displacements of two longitudinal members shown in Fig. 4.

Denote by $q_{12 U}, q_{12 L}$ the shearing forces acting in deck plates and bottom plates in the $x$-direction. Taking into account of the shear deformation only, we obtain,

$$
\begin{aligned}
& q_{12 U}=G \frac{t_{U}}{b_{U}}\left(u_{1 U}-u_{2 U}\right) \\
& q_{12 L}=G \frac{t_{L}}{b_{L}}\left(u_{1 L}-u_{2 L}\right) .
\end{aligned}
$$

where $u_{1 U}$ and $u_{1 L}$ are the longitudinal displacements at the deck line and the bottom line of the side shell part respectively, and $u_{2 U}$ and $u_{2 L}$ are those of the longitudinal bulkhead part respectively.

(4) Equation of Equilibrium

Let us consider an element cut out as shown in Fig.4. Considering the equilibrium of all the forces and moments, we obtain the following equations :

$$
\begin{aligned}
\frac{d S_{1}}{d x} & =p_{12}-f_{1} \\
\frac{d M_{1}}{d x} & =S_{1}-e_{1 U} q_{12 U}+e_{1 L} q_{12 L} \\
\frac{d N_{1}}{d x} & =q_{12 U}+q_{12 L} \\
\frac{d S_{2}}{d x} & =-p_{21}-f_{2} \\
\frac{d M^{2}}{d x} & =S_{2}+e_{2 U} q_{12 U}-e_{1 L} q_{12 L} \\
N_{2} & =-N_{1}
\end{aligned}
$$

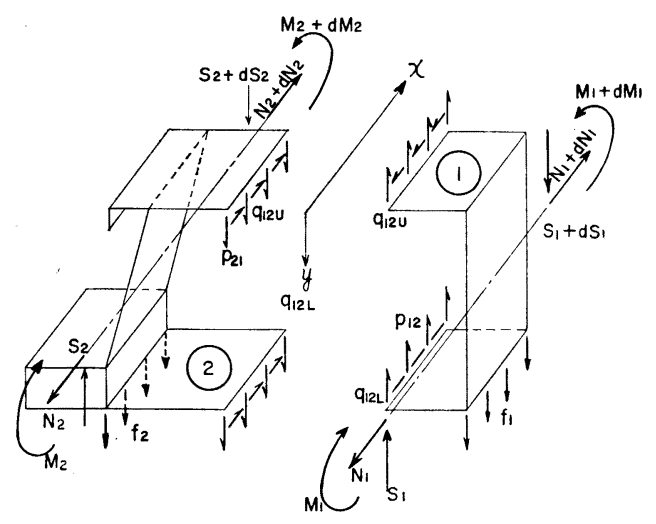

Fig. 4 Equilibrium of Elements

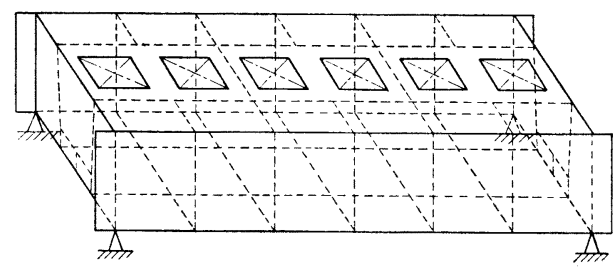

Fig. 5 Boundary Condition
The stress resultants expressed in terms of the displacement compnents $y_{1}, y_{2}, \varphi_{1}, \varphi_{2}, u_{1}$ and $u_{2}$ are all given as follows :

$$
\begin{aligned}
& S_{1}=G A_{s 1}\left(\frac{d y_{1}}{d x}-\varphi_{1}\right) \\
& M_{1}=-E I_{1} \frac{d \varphi_{1}}{d x} \\
& N_{1}=E A_{N 1} \frac{d u_{1}}{d x} \\
& S_{2}=G A_{s 2}\left(\frac{d y_{2}}{d x}-\varphi_{2}\right) \\
& M_{2}=-E I_{2} \frac{d \varphi_{2}}{d x} \\
& N_{2}=-N_{1}
\end{aligned}
$$

Substitutiag (1.1), (1.2) and (1.4) into (1.3), we can get the fundamental differential? equation shown in Appendix 1.

\section{(5) Boundary Condition}

The authors consider the following boundary conditions for the fundamental differential equation :

(a) The side shell is supported at the engine room front bulkhead and the fore peak bulkhead. In other words, the longitudinal 
bulkhead is hanged by the transverse bulkhead at those points.

(b) Each longitudinal member is connected at the position of transverse bulkheads (transverse water-tight bulkheads and swash bulkheads), which deform by shearing forces due to the relative deflection.

(c) All the normal forces, deflections, rotations of cross section and elongation of members are continuous at the position of transverse bulkheads in wing tanks.

(6) Numerical Calculation

Numerical Calculation of the fundamental differential equation is carried out by the electronic computer. The method of calculation is shown in Appendix 2.

\section{Examples of Numerical Calculations}

Using the method of calculation as shown in Chapter 2, we calculated the transverse strength of a large ore carrier. The results are presented in this Chapter. The load condition used in these examples is the full load condition in still water.

\section{1 Shear Deformation of Wing Tanks}

The values of rigidity of structural members and loads are listed in Table 1 , and the results are shown in Fig.6. From these results the following things are found :

Table-I. Structural a Load Elements (I)

\begin{tabular}{|c|c|c|c|c|c|c|c|c|}
\hline Structural & Elem & ments & & & oad & lements & $(\mathrm{Kg} / \mathrm{cr}$ & \\
\hline & & Volues & Load & Member & Side $\mathrm{S}$ & hell Part & Longl B! & HD Part \\
\hline erements & & varues & Cond. & Region & Weight & Buoyancy & Weight & Buoyancy \\
\hline & & & & No. 1 & 82.4 & 593.6 & 1948.8 & 1313.2 \\
\hline Shear Rigidity & & & $=$ & 2 & $"$ & $n$ & $"$ & $"$ \\
\hline K T.W.T B- BD & $\mathrm{kg}_{\mathrm{km}}$ & $2.151 \times 10^{6}$ & 0 & 3 & $"$ & $"$ & $"$ & $"$ \\
\hline K ORD. TRANS & " & $0.1872 "$ & 0 & 4 & 1 & $"$ & $"$ & $"$ \\
\hline & & & & 5 & - & $\cdot$ & $"$ & $n$ \\
\hline Shear Rigidity & & & & 6 & $\div$ & $"$ & $n$ & - \\
\hline Side Shell Part. & $\mathrm{kg}$ & $2.336 \times 10^{9}$ & $\begin{array}{l}\text { E } \\
\text { w }\end{array}$ & 7 & $"$ & 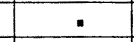 & $"$ & $n$ \\
\hline Longe $B^{\text {HD }}$ Part & 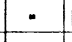 & $1.580^{n}$ & $\vec{w}$ & 8 & $"$ & $"$ & $"$ & $"$ \\
\hline Bending Rigidity & & & & 9 & - & $"$ & " & " \\
\hline Side Shell Part & $\mathrm{kg} \cdot \mathrm{m}^{2}$ & $7.302 \times 10^{15}$ & & 10 & $"$ & $"$ & $"$ & $"$ \\
\hline Longl B $\mathrm{BD}$ Part & $" 1$ & $12.24 n$ & & No. 1 & 82.4 & 636.9 & 1910.7 & 1408.8 \\
\hline Tenside Rigidity & & & g & 2 & $"$ & 633.2 & 28040 & 1400.7 \\
\hline Side Shell Part & kg & $16.07 \times 10^{9}$ & $=$ & 3 & $"$ & 622.2 & 1464.7 & 1376.5 \\
\hline Longl BHD Part & $"$ & $2440 "$ & : & 4 & $n$ & 611.2 & 28040 & 1352.1 \\
\hline & & & & 5 & $"$ & 591.5 & 1218.0 & 1308.6 \\
\hline$\beta_{u}$ & - & $3.264 \times 10^{-3}$ & $\frac{0}{2}$ & 6 & $"$ & 579.2 & 1035.8 & 1281.2 \\
\hline$B L$ & - & $2475 \ldots$ & $\overrightarrow{\underline{L}}$ & 7 & $"$ & 568.2 & 1103.7 & 12569 \\
\hline$e_{\text {IU }} / \mathrm{D}$ & - & 0.5303 & 过 & 8 & $\cdot$ & 557.2 & 1447.7 & 1232.6 \\
\hline e2u/D & - & 0.5977 & ш & 9 & $"$ & 546.2 & 2770.4 & 1208.3 \\
\hline & & & & 10 & $"$ & 535.2 & 1447.7 & 1184.0 \\
\hline
\end{tabular}

(a) The ratio of the shear deformation of the transverse ring in the middle part of a wing tank to that of the transversverse water-tight bulkhead is from 1.6 to 1.7 in the case of this calculation. The shear deformation of transverse watertight bulkhead, therefore, must be taken into consideration, when relative deflection is calculated in way of cutting out 1 tank part.

(b) Relative deflection becomes about 40 percent larger at the position of transverse rings in the middle part of a wing tank and 20 percent larger at the position of watertight bulkheasds in eccentric loading than in uniform loading.

\section{2 Bending Moment Diagram and Shearing Force Diagram}

The values of rigidity and scantlings of structural members and loads are listed in Table 2 . The 

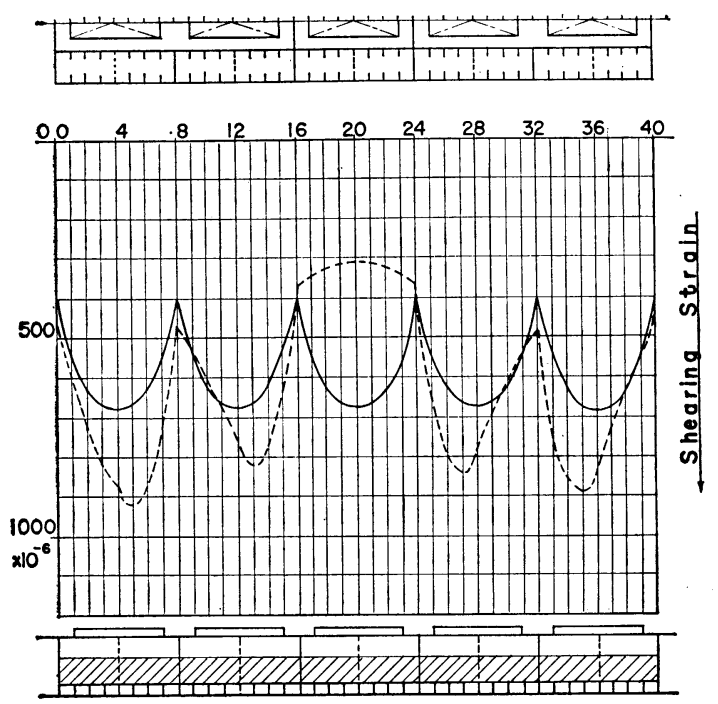

(a) Even Loading. (-)

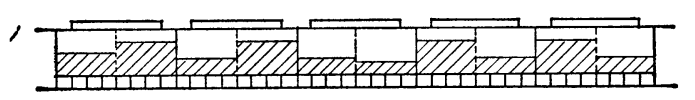

(b) Eccentric Loading. (----)

Fig. 6 Shearing Deformation

Table-2. Structural a Load Elements (2)

\begin{tabular}{|c|c|c|c|c|c|c|c|c|c|}
\hline \multicolumn{2}{|l|}{$1 \mathrm{t} \mathrm{e} \mathrm{m}$} & \multicolumn{8}{|c|}{ Me m bers } \\
\hline Elements & Unit & $A B$ & $B C$ & $C D$ & $D E$ & $E F$ & FG & GB & DG \\
\hline Length of Spar & $\mathrm{cm}$ & 608 & 947 & 735 & 870 & 635 & 868 & 745 & 797 \\
\hline $\begin{array}{l}\text { Effectlve Br- } \mathrm{Br}- \\
\text { eadth of Plate }\end{array}$ & $"$ & 240 & 210 & 176 & 191 & 154 & 154 & 206 & - \\
\hline She or & $10^{9}$ & $\times 10^{9}$ & $\times 10^{9}$ & $\times 10^{9}$ & $\times 10^{9}$ & $\times 10^{9}$ & $\times 10^{9}$ & $\times 10^{9}$ & $\times 10^{9}$ \\
\hline Pigidity & $\mathrm{kg}$ & 03279 & 0.1478 & 0.1082 & 0.0929 & 0.0695 & 0.0929 & 0.0929 & 0.0703 \\
\hline Bending & $10^{13}$ & $\times 10^{13}$ & $\times 10^{13}$ & $\times 10^{13}$ & $\times 10^{13}$ & $\times 10^{13}$ & $\times 10^{13}$ & $\times 10^{13}$ & $\times 10^{13}$ \\
\hline Rigidity & $\mathrm{kg} \cdot \mathrm{cm}^{2}$ & 7.606 & 0.5968 & 0.4133 & 0.4017 & 0.1459 & 0.3158 & 0.3652 & 0.0761 \\
\hline $\begin{array}{l}\text { Loadacting } \\
\text { on Left End }\end{array}$ & $\mathrm{kg} / \mathrm{cm}$ & -533 & 450 & 413 & 131 & 0 & 0 & 227 & 0 \\
\hline $\begin{array}{l}\text { Lood acting } \\
\text { on Right End }\end{array}$ & $"$ & -533 & 450 & 131 & 0 & 0 & 227 & 441 & 0 \\
\hline
\end{tabular}

Note: Load acting inward is taken as a positive.

results are shown in Fig. 7 (a), ( b ). They correspond to the transverse ring in the middle part of a wing tank in the eccentric load condition. From these results the following things are found:

(1) Eelative deflection has great influence on bending moments and shearing forces.

(2) The shapes of bending moment diagram and shearing force disgram vary remarkably according to the magnitude of the relative deflection.

\section{3 Stresses in Joints of Structural Members}

In investigating the transverse strength we need ultimately the stress distribution of transverse rings.

It is easy to know normal stresses and shearing stresses in the middle part of structural members, but is very difficult to know stresses in joints of structural members. There are many methods for calculating the stresses in joints, for example, Osgood's theory ${ }^{4}$, Terada's theory ${ }^{5}$, etc. But these theories do not consider distributed loads on the joints directly and, moreover, are made for compara- 


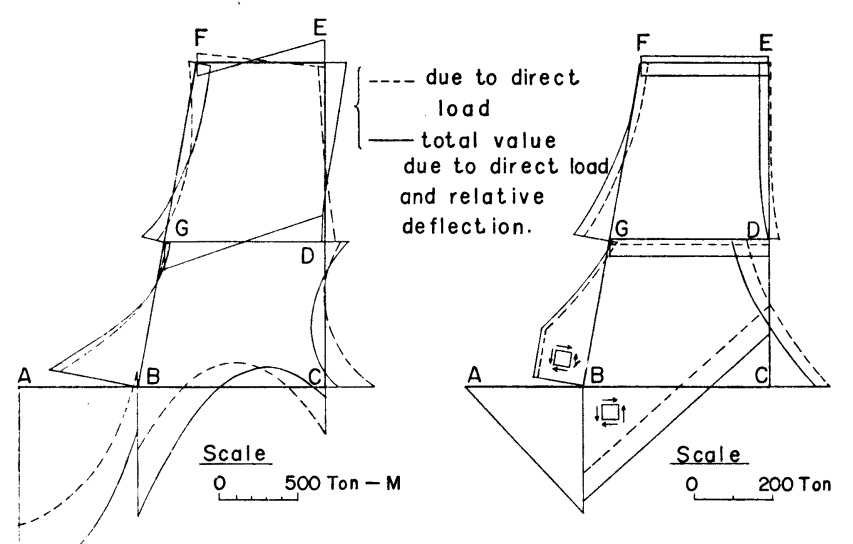

(a) Bending Moment Diagram (b) Shearing Force Diagram

Fig. 7 Results of Calculation of Transverse Ring

-Full Load Cotdition in Still Water (Eccentric Loading) -

tively simple joints. So there are many problems when we apply these theories on actual ships. We think, therefore, that further researches on his problem should be done hereafter.

Taking into consideration these problems in this paper, we developed Terada's theory and made an approximate method of calculation of stresses in oints.

The stresses in joints estimated by this method are shown in Fig. 8(a), (b). From these reults we know that relative deflection has great influ-

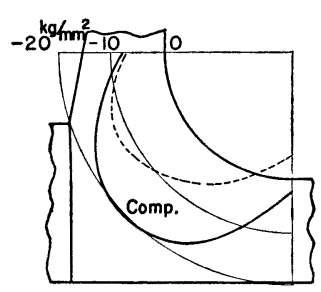

(a) Long? $B^{\text {Hi }}$ Side

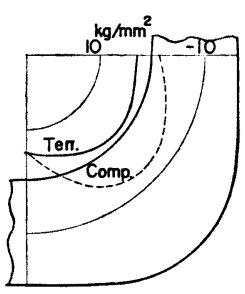

(b) Bilge Corner

$\left\{\begin{array}{l}\text { Due to Direct Load } \\ \text { - Total Stress }\end{array}\right.$

Fig. 8 Stress Distribution at Joints (Full Load Condition in Still Water) ence on the stresses, too.

\section{Some Considerations on Relative Deflection}

We knew from the results of numerical calculations shown in Chapter 3 that stresses induced by relative deflection between side shells and longitudinal buklheads has great influence on the strength of transverse rings. Consequently it becomes necessary to make the relative deflection small in order to preserve the transverse strength. In this Chapter the effect of shear rigidity of swash bulkheads and transverse rings on relative deflection are discussed.

\section{1 Effect of Shear Rigidity of Swash Bulkheads}

Swash bulkheads are set in wing tanks at some intervals in order to restrain the motion of inner fluid and preserve the transverse strength. There are two types of swash bulkheads; one is reinforced ordinary transverse ring what is called strong transverse ring type, and the other is what is called

Table - 3. Shear Rigidity of a Swash BHD

\begin{tabular}{|c|c|c|c|}
\hline Case No. & $\frac{K \text { SWASH }}{K \text { W.T. } B \text { HD }}$ & $\frac{\text { K SWAEH Q }}{\text { KORD }}$ & Remorks \\
\hline I. & 0.0875 & {$[1.000]$} & No Swash B \\
\hline 2. & 0.175 & {$[2.000]$} & Strong Trans ${ }^{s}$ Ring Type \\
\hline 3. & 0.262 & {$[3.000]$} & Strong Trans. Ring Type \\
\hline 4. & 0.750 & $8.571]$ & Perforated Plane Type \\
\hline 5. & 1.000 & {$[11.43]$} & Water Tight $B \underline{\text { HD }}$ \\
\hline
\end{tabular}



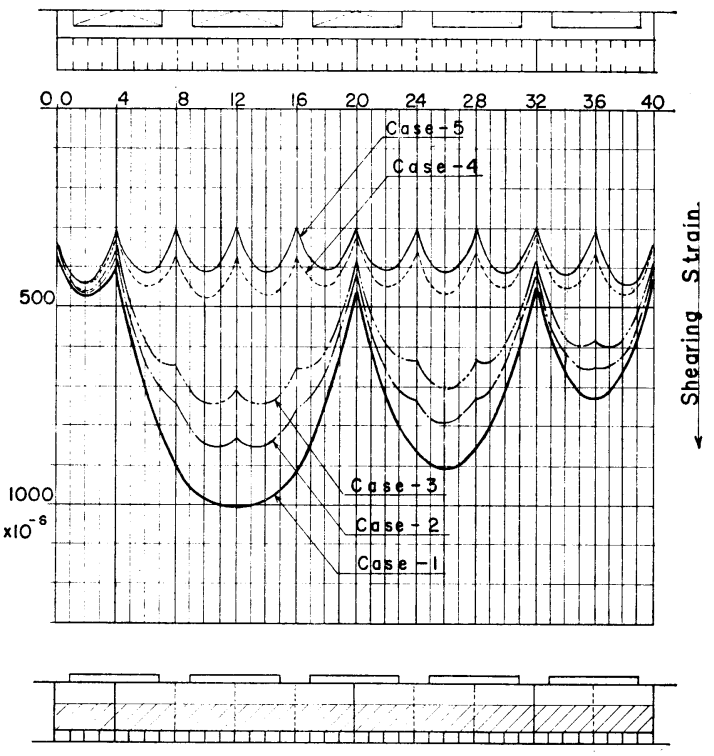

Fig. 9 Effects of Shear Rigidity of Swash Bulkheads
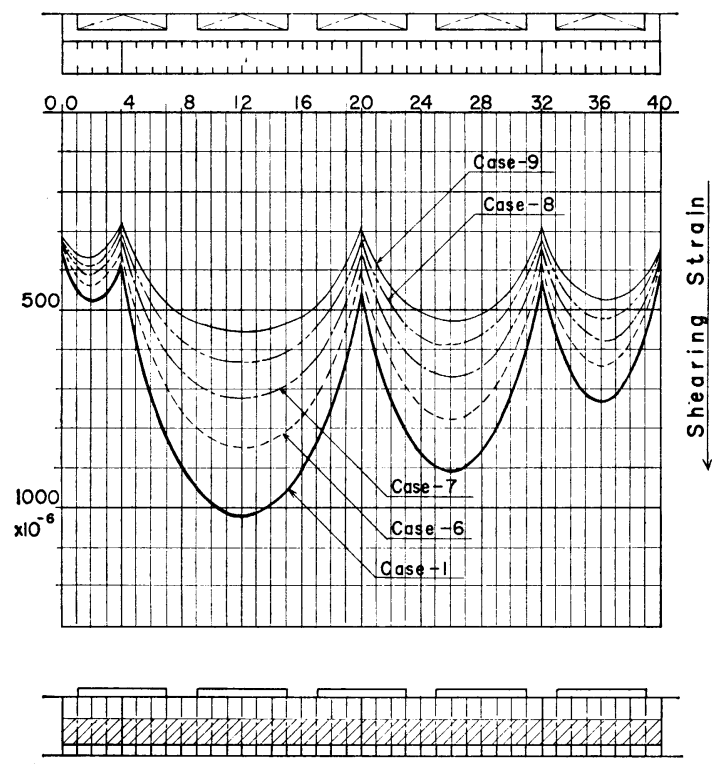

Fig. 10 Effects of Shear Rigidity of Ordinary Trans. Rings.

Table - 4 Shear Rigidity of an Ord. T. Ring.

\begin{tabular}{|c|c|c|}
\hline Case No. & $\frac{\text { K(ORD.T.RING) }}{\text { K(ORD.T.RING)O }}$ & Remarks. \\
\hline 1 & 1.00 & No. Swash B HD \\
\hline 6 & 1.25 & $"$ \\
\hline 7 & 1.50 & $"$ \\
\hline 8 & 1.70 & $"$ \\
\hline 9 & 2.00 & $"$ \\
\hline Note : K (ORD. T. RING) $0=0.1872 \times 10^{6} \mathrm{Kg} / \mathrm{cm}$
\end{tabular}

perfurated plane type which has many small holes. In order to examine the effect of swash bulkheads upon relative deflection, some numerical calculations were done in such condition as shown in Table 3 , where the shear rigidity of swash bulkheads is varied systimatically.

The results are given in Fig. 9. In Fig. 9 the Case No. 5 corresponds to the type which was used usually before long tanks are adopted. From these results we can observe that perforated plane type is effective for the purpose of preserving the transverse strength.

\section{2 Eff ect of Shear Rigidity of Trans- verse Rings}

Let us consider to reinforce ordinary transverse rings for making relative deflection small. For the purpose of investigation this effect, some numerical calculations were done in such condition as shown in Table 4 , where the shear rigidity of ordinary transverse rings is varied systimatically.

The results are given in Fug. 10.

From these results we can observe the following thing : In order to make the relative deflection of long tanks with no swash bulkhead as small as that of previous wing tanks, it is necessary to reinforce the transverse rings so as to have shear rigidity two or three times as strong.

What we must notice in this case is that reinforcing a transverss ring brings about the increase of bending moments and shearing forces induced by unit relative deflection, though it increases the ultimate strength of the transverse ring itself. Consequently it becomes necessary, ultimately, to estimate the stress distribution in discussing the transverse strength.

\section{Conclusion}

In this paper the transverse strength of a large ore carrier which is in the full load condition in still water was resarched. As the results of this resarch the followign 
things were found :

(1) Relative deflection between side shell and longitudinal bulhkead has great effect on bending moments, shearing forces and stresses of transverse rings, so it must be considered in discussing the transverse strength.

(2) About half of the stress in joint of the transverse ring is what induced by relative deflection.

(3) For the purpose of making relative deflection small, to set swash bulkheads of perforated plane type is effective.

The authors wishes to acknowledge to Mr. Okabe (Nagasaki Shipyard, M. H. I. Co., Ltd.) and Mr. Ooi (Yokohama Shipyard, M. H. I. Co., Ltd.) for their valuable advices and discussion and also to Mr. Hagiwara and Mr. Nakajima (Hiroshima Technical Institute, M. H. I. Co., Ltd.) and others for their kind assistance in this works.

\section{References :}

1) M. Yamagosh \& K. Kagawa : "Shearing Deformation of Wing Tanks". Journal of the Society of Naval Architects of West Japan, No.29.

2) J. Yagi : "Deformations of Hatch Openings and Wing Tanks". Transactions of the Society of Naval Architects of Japan, No. 440.

3) For example, E. Steneroth: "Oo the Transverse Strength of Tankers". T. R. I. T. Stockholm(1955). And I. Yamaguchi : "On the Approximate Method for Transverse Strength Calculation". Journal of the Society of Naval Architects of Japan, Vol. 109.

4) W.R. Osgood : “A Theory of Flexure for Beams with Nonparallel Extreame Fibers”. Journal of Applied Mechanics, 1939.

5) Y.Terada : "Approximate Method of Analysis on the Stress Distribution at Joints of Structural Members in Oil Takerns". Jounrnal of the Society of Naval Architects of Japan, Vol. 109.

\section{Appendix-1. Fundamental Differential Equation for Longitudinal Members}

Substituting (1.1), (1.2) and (1.4) to (1.3), we obtain following formula as the fundamental differential equation for this problem.

$$
\left.\begin{array}{rl}
G A_{s 1} \frac{d}{d x}\left(\frac{d y_{1}}{d x}-\varphi_{1}\right)=k\left(y_{1}-y_{2}\right)-f_{1} \\
-E I_{1} \frac{d^{2} \varphi_{1}}{d x^{2}}= & G A_{s 1}\left(\frac{d y_{1}}{d x}-\varphi_{1}\right) \\
& -G\left(\frac{e_{1 U} t_{U}}{b_{U}}-\frac{e_{1 L} t_{L}}{b_{L}}\right) u_{1}+G\left(\frac{e_{1 U} t_{U}}{b_{U}}-\frac{e_{1 L} t_{L}}{b_{L}}\right) u_{2} \\
& -G\left(e_{1 U}^{2} \frac{t_{U}}{b_{U}}+e_{1 L}{ }^{2} \frac{t_{L}}{b_{L}}\right) \varphi_{1}+G\left(e_{1 U} e_{2 U} \frac{t_{U}}{b_{U}}+e_{1 L} e_{2 L} \frac{t_{L}}{b_{L}}\right) \varphi_{2} \\
E A_{N 1} \frac{d^{2} u_{1}}{d x^{2}=} & G\left(\frac{t_{U}}{b_{U}}+\frac{t_{L}}{b_{L}}\right) u_{1}-G\left(\frac{t_{U}}{b_{U}}+\frac{t_{L}}{b_{L}}\right) u_{2} \\
& +G\left(e_{1 U} \frac{t_{U}}{b_{U}}-e_{1 L} \frac{t_{L}}{b_{L}}\right) \varphi_{1}-G\left(e_{2 U} \frac{t_{U}}{b_{U}}-e_{2 L} \frac{t_{L}}{b_{L}}\right) \varphi_{2} \\
G A_{s 2} \frac{d}{d x}\left(\frac{d y_{2}}{d x}-\varphi_{2}\right)=-k\left(y_{1}-y_{2}\right)-f_{2} \\
-E I_{2} \frac{d^{2} \varphi_{2}}{d x^{2}=} & G A_{s 2}\left(\frac{d y_{2}}{d x}-\varphi_{2}\right) \\
+ & G\left(e_{2 U} \frac{t_{U}}{b_{U}}-e_{2 L} \frac{t_{L}}{b_{L}}\right) u_{1}-G\left(e_{2 U} \frac{t_{U}}{b_{U}}-e_{2 L} \frac{t_{L}}{b_{L}}\right) u_{2} \\
+ & G\left(e_{1 U} e_{2 U} \frac{t_{U}}{b_{U}}+e_{1 L} e_{2 L} \frac{t_{L}}{b_{L}}\right) \varphi_{1}-G\left(e_{2 U} \frac{t_{U}}{b_{U}}+e_{2 L} \frac{t_{L}}{b_{L}}\right) \varphi_{2}
\end{array}\right\}
$$

where,

$y:$ total deflection

$\varphi$ : angle of rotation of cross section due to bending

$u$ : displacement of neutral axis in the longitudinal direction 
$A_{s}$ : effective cross sectional area for shear deflection

$I$ : moment of inertia of cross section

$A_{N}$ : effective cross sectional area for elongation

$k$ : spring constant devided by 1 -transverse ring spacing

$f$ : externsl force, downward positive

$e_{U}, e_{L}, t_{U}, t_{L}, b_{U}, b_{L}$ : scantlings shown in Fig. 4 ( b ).

$E \& G$ : Young's modulus and modulus in shear and suffix 1 and 2 denote those of side shell part and longitudinal part, respectively.

\section{Appendix-2. Method of Calculation of Fundamental Differential Equation}

General Theory...Here we consider a problem of determining numerical solution of a general boundary value problem of linear differential equation in $\left(x_{0}, x_{n}\right)$.

$$
\frac{d \boldsymbol{Y}}{d x}=A(x) \cdot \boldsymbol{Y}+\boldsymbol{F}(x)
$$

Practically, with suitable subdivision of whole interval, we can assume that $A(x)$ and $\boldsymbol{F}(x)$ are piecewise constant, then we have

$$
\frac{d \boldsymbol{Y}}{d x}=A_{i} \cdot \boldsymbol{Y}+\boldsymbol{F}_{i}
$$

where $A_{i}$ is a non-singular constant matrix and $\boldsymbol{F}_{i}$ is a consstant column vector in each subinterval $\left(x_{i-1}, x_{i}\right)$.

Let $\boldsymbol{y}_{i}=\boldsymbol{y}\left(x_{i}\right)$, then solution in $\left(x_{i-1}, x_{i}\right)$ has the form

$$
\boldsymbol{Y}=e^{A_{i}\left(x-x_{i-1}\right)} \boldsymbol{Y}_{i-1}+A^{-1}\left(e^{A_{i}\left(x-x_{i-1}\right)}-I\right) \boldsymbol{F}
$$

where $I$ is an identity matrix and $e^{A x}$ is a matrix defined as

$$
e^{A x}=\sum_{j=0}^{\infty} \frac{A^{j} x^{j}}{j !}
$$

In ordinary engineering problems, boundary conditions can quite generally be formulated at each ${ }_{-} x_{\imath}$ with suitable materices $E_{i}, H_{i}, T_{i}, B_{i}$ and vectors $\boldsymbol{G}_{\imath}, \boldsymbol{C}_{i}$ as

$$
\begin{aligned}
& \left\{\begin{array}{l}
E_{\imath} \boldsymbol{Y}_{i-\mathrm{c}}=\boldsymbol{G}_{i}+H_{i} \widetilde{\boldsymbol{Z}}_{i} \\
\boldsymbol{Y}_{i+0}=T_{i} \boldsymbol{Y}_{i-1}+B_{i} \boldsymbol{Z}_{\imath}+\boldsymbol{C}_{\imath}
\end{array}(i=1,2, \cdots, n-1)\right. \\
& \boldsymbol{Y}_{\mathbf{0}}=B_{0} \boldsymbol{Z}_{0}+\boldsymbol{C}_{0} \quad(i=0) \\
& E_{n} \boldsymbol{Y}_{n}=\boldsymbol{G}_{n} \quad(i=n)
\end{aligned}
$$

where $\boldsymbol{Z}_{i}$ is a possible unknown vector at $x=x_{i}$ and $\widetilde{\boldsymbol{Z}}_{i}=\left(\begin{array}{c}\widetilde{\boldsymbol{Z}}_{i-1} \\ \boldsymbol{Z}_{i}\end{array}\right)$ with $\widetilde{\boldsymbol{Z}}_{0}=\boldsymbol{Z}_{0}$ and $\boldsymbol{Z}_{n}$ is void.

Above formulation of boundary conditions is able to involve the problem with changing the dimension of the solution space.

Now let

$$
\begin{aligned}
& R_{i}=e^{A_{i}\left(x x_{i}-x_{i-1}\right)} \\
& K_{i}=A_{i}^{-1}\left(e^{A_{i}\left(x_{i}-x_{i-1}\right)}-I\right)
\end{aligned}
$$

and let

$$
\begin{aligned}
& \widetilde{B}_{i}=\left(T_{i} \cdot R_{i} \cdot \widetilde{B}_{i-1}, B_{i}\right) \\
& \widetilde{\boldsymbol{C}}_{i}=T_{i} \cdot R_{i} \cdot \widetilde{\boldsymbol{C}}_{i-1}+T_{i} \cdot K_{i} \cdot \boldsymbol{F}_{i}+\widetilde{\boldsymbol{C}}_{i} \\
& \text { with } \quad \widetilde{B}_{0}=B, \quad \widetilde{\boldsymbol{C}}_{0}=\boldsymbol{C}_{0},
\end{aligned}
$$

then we obtain

$$
\begin{aligned}
& \boldsymbol{Y}_{i}^{+0}=\widetilde{B}_{i} \widetilde{\boldsymbol{Z}}_{i}+\widetilde{\boldsymbol{C}}_{i}, \\
& \boldsymbol{Y}_{i+1}^{-0}=R_{i+1}\left(\widetilde{B}_{i} \cdot \widetilde{\boldsymbol{Z}}_{i}+\widetilde{\boldsymbol{C}}_{i}\right)+K_{i+1} \cdot \boldsymbol{F}_{i+1}
\end{aligned}
$$

By (A 2.5) we have

$$
E_{i+1} \cdot \boldsymbol{Y}_{i+1}^{-0}=E_{i+1}\left(R_{i+1}\left(\widetilde{B}_{i} \cdot \widetilde{\boldsymbol{Z}}_{\iota} \div \widetilde{\boldsymbol{C}}_{i}\right)+K_{i+1} \cdot \boldsymbol{F}_{i+1}\right)
$$




$$
\begin{aligned}
& =\left(E_{i+1} \cdot R_{i+1} \cdot \widetilde{B}_{i}, 0\right) \widetilde{\boldsymbol{Z}}_{i+1}+E_{i+1} \cdot R_{i+1} \cdot \widetilde{\boldsymbol{C}}_{i}+E_{i+1} \cdot K_{i+1} \cdot \boldsymbol{F}_{i+1} \\
& =\boldsymbol{G}_{i+1}+H_{i+1} \cdot \widetilde{\boldsymbol{Z}}_{i+1}
\end{aligned}
$$

honce

$$
\left[\left(E_{i+1} \cdot R_{i+1} \cdot \widetilde{B}_{i}, 0\right)-H_{i+1}\right] \cdot \widetilde{\boldsymbol{Z}}_{i+1}=\boldsymbol{G}_{i+1}-E_{i+1} \cdot R_{i+1} \cdot \widetilde{\boldsymbol{C}}_{i}-E_{i+1} \cdot K_{i+1} \cdot \boldsymbol{F}_{i+1}
$$

By solving equation (A 2.18) $(i=0,1,2, \cdots, n-1)$ simultaneously, we have $\widetilde{\boldsymbol{Z}}_{n-1}$, i. e. all $\boldsymbol{Z}_{i}(i=0,1$, $\cdots, n-1)$, then our boundary value problem is changed into an initial value problem and it is solved by (A 2.3). 